\title{
Synergistic effects of mineral fibres and cigarette smoke on the production of tumour necrosis factor by alveolar macrophages of rats
}

\author{
Yasuo Morimoto, Masamitsu Kido, Isamu Tanaka, Akihiro Fujino, Toshiaki Higashi, \\ Yasuyuki Yokosaki
}

\begin{abstract}
The objective of this study was to evaluate the combined effects of mineral fibres and cigarette smoke on the production of tumour necrosis factor (TNF) by alveolar macrophages. Rats were exposed to cigarette smoke in vivo, and production of TNF by alveolar macrophages was measured in the presence of mineral fibres in vitro. For smoke exposure, rats were divided into two groups. Five were exposed to a daily concentration of $10 \mathrm{mg} / \mathrm{m}^{3}$ of cigarette smoke for an eight hour period, and five rats (controls) were not exposed to smoke. Bronchoalveolar lavage was performed after exposure to smoke and the recovered alveolar macrophages were incubated with either chrysotile or ceramic fibres on a microplate for 24 hours. Activity of TNF in the supernatant was determined by the L929 fibroblast cell bioassay. When alveolar macrophages were not stimulated by mineral fibres, production of TNF by rats exposed to smoke and unexposed rats was essentially the same. When alveolar macrophages were stimulated in vitro by chrysotile or ceramic fibres, production of TNF by alveolar macrophages from rats exposed to smoke was higher than that by alveolar macrophages from unexposed rats. The findings suggest that cigarette smoke and mineral fibres have a synergistic effect on TNF production by alveolar macrophages.
\end{abstract}

(British Fournal of Industrial Medicine 1993;50;955-960)

Division of Respiratory Disease

Y Morimoto, Y Yokosaki, M Kido

Department of Environmental Health Engineering

I Tanaka

Department of Health Policy and Management,

University of Occupational and Environmental

Health, Japan

T Higashi, A Fujin
Epidemiological and clinical studies ${ }^{12}$ have indicated that asbestos workers who smoked cigarettes had a higher incidence of asbestos induced disease than those who did not. It is generally accepted that smoking is associated with a higher risk of carcinoma of the lung, ${ }^{1}$ but its association with asbestosis is controversial. Weiss ${ }^{2}$ reviewed 14 prevalence studies and seven cohort studies of asbestos workers in which information on smoking habits was available. Most showed a positive interaction between smoking and asbestos, suggesting that smoking and asbestos act synergistically in the development of fibrosis, but the mechanism of this interaction is unknown.

Alveolar macrophages play a critical part in pathogenesis of lung fibrosis. Early studies ${ }^{3-5}$ suggested that phagocytosis of inhaled fibres at the alveolar level caused the death of alveolar macrophages, leading to the release of enzymes that subsequently cause asbestosis. Some studies suggested that cytoactivation occurs, resulting in a stimulation of the immune system of the lung, including the host defence system. ${ }^{6}$ These results suggest that a network of signals from cells, especially alveolar macrophages, mediate cell to cell interaction and that this signal network is involved in normal lung homeostasis. ${ }^{7}$ Disturbances to this network cause lung injury, which then leads to fibrosis. Cytokines play key parts in signalling among cells. Tumour necrosis factor (TNF), one of these cytokines, has a regulatory effect on cells and is involved in lung injury and fibrosis.? Alterations in the production of this cytokine can be an indicator of cytoactivation.

The effects of mineral fibres in the lungs, especially asbestos, have been widely studied. Recently, various types of man made mineral fibres (MMMFs) have been developed as substitutes for asbestos, and the demand for these products has been increasing. Some MMMFs are believed to have the same adverse biological effects as asbestos because of their similar physicochemical properties. $^{8}$ 
The effects of cigarette smoke, and asbestos or MMMFs, on cytoactivation in the lung have not been investigated. To determine the combined effect of the two agents on the production of TNF by alveolar macrophages, we studied in vitro the effects of mineral fibres on rat alveolar macrophages that had been exposed to cigarette smoke in vivo.

\section{Materials and methods} FIBRES

The fibres used in this study were Canadian chrysotile, (LAB chrysotile class 6, Quebec) and alumina silicate ceramic fibres (Nippon Steel Chemical Co, Japan). The samples were milled and made into an aerosol in a chamber by means of a dust generator. The resulting aerosol was processed with a cascade impactor air sampler (Andersen type, model AN-200, Shibata Scientific Technology Ltd, Japan) to obtain respirable fibres. ${ }^{9}$ When processed in this way, both types of fibres had a mass median aerodynamic diameter of about $3 \cdot 1 \mu \mathrm{m}$.

For characterisation by scanning electron microscopy, fibres were suspended in distilled water and aliquots filtered through $0.22 \mu \mathrm{m}$ millipore membrane filters (Toyo Roshi LNC, CA). Specimens were dried at a critical point, sputter coated with platinum, and examined under a scanning electron microscope (Hitachi S-700, Japan).

CIGARETTE SMOKE EXPOSURE SYSTEM

For administration of cigarette smoke, we used the passive exposure system developed by Tanaka $e t$ al (fig 1). This system maintained a constant concentration of aged sidestream cigarette smoke aerosol during exposure. ${ }^{10}$

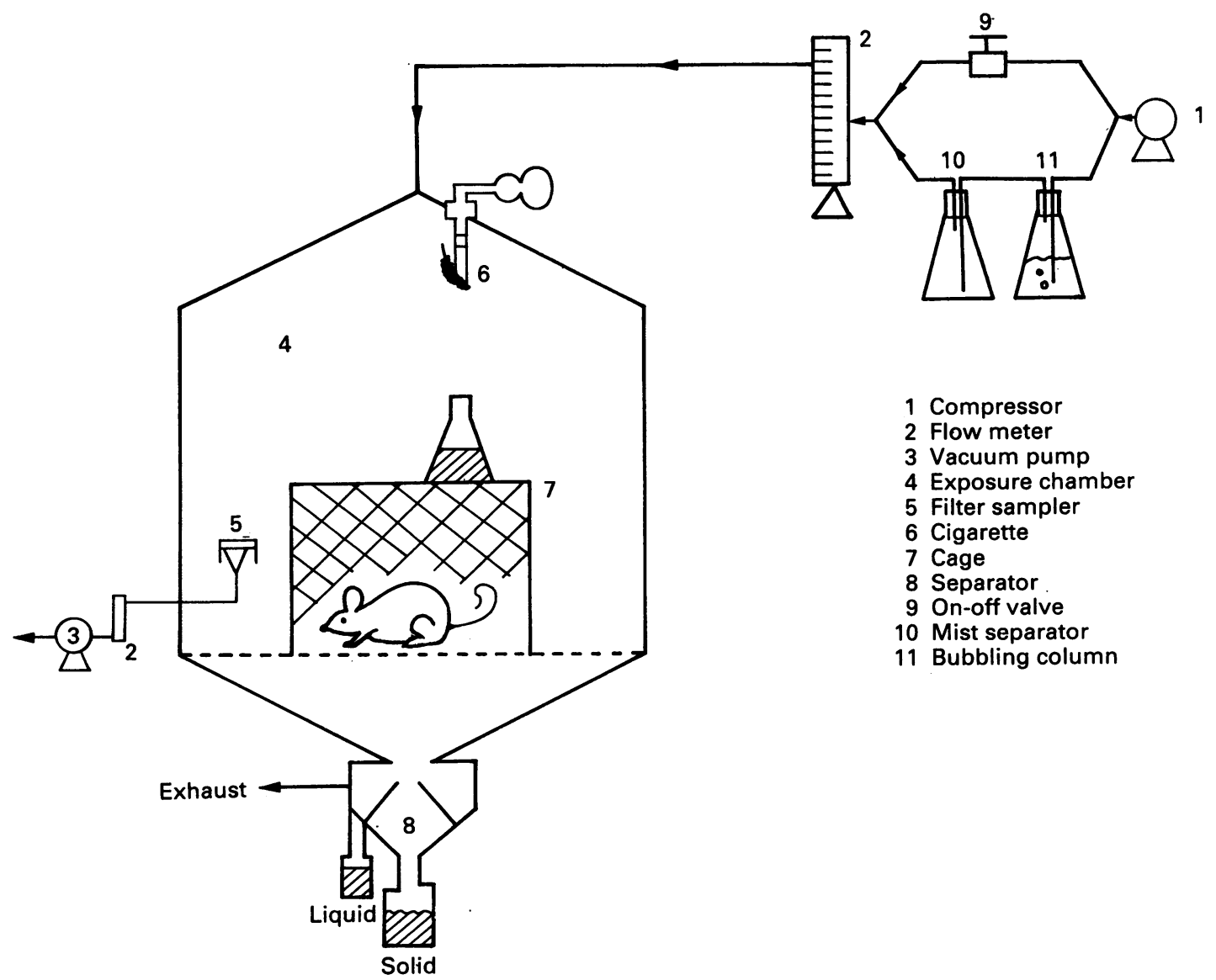

Figure 1 Schematic diagram of the system for cigarette smoke exposure. 
EXPERIMENTAL DESIGN

Male (nine week old) Wistar rats (Kyudou Co, Japan) were maintained in a chamber and observed for four to five days before these experiments. Rats were divided into a group exposed to smoke $(n=5)$ and an unexposed $(n=5)$ group. The first were housed in the exposure chamber and 40 cigarettes were smoked for eight hours. The concentration of cigarette smoke in the chamber was $10 \mathrm{mg} / \mathrm{m}^{3}$ as measured gravimetrically from glass fibre filter samples. The concentration of CO was $79 \mathrm{ppm}$, which is below the concentration that induces specific biological effects. The chamber volume was 1001 and the flow rate in the chamber was $501 / \mathrm{min}$. After exposure, the animals were killed and free cells recovered from the lung by bronchoalveolar lavage.

\section{BRONCHOALVEOLAR LAVAGE AND PREPARATION} OF SUPERNATANT FROM ALVEOLAR MACROPHAGES. Each animal was anaesthetised by an intraperitoneal injection of phenobarbitone and killed by exsanguination. The trachea was cannulated, and the lungs lavaged with a total volume of $50 \mathrm{ml}$ saline in 6 to $8 \mathrm{ml}$ aliquots. The bronchoalveolar lavage fluid was then centrifuged $(1200 \mathrm{~g}$ for 10 minutes) and the supernatant removed. The cell pellet was resuspended in RPMI 1640 medium (Whittaker MA Bioproducts, Walkersville, MD) supplemented with $5 \%$ inactivated fetal bovine serum (GIBCO Laboratories, Grand Island, NY). Cells were counted in a haemacytometer chamber and their viability determined by trypan blue exclusion. The cell suspension was adjusted to a concentration of $1 \times 10^{6} \mathrm{cells} / \mathrm{ml}$. After the addition of chrysotile or ceramic fibres to the suspensions, the cells were cultured for 24 hours on cell culture plates (Nunc, Kamstrup, Denmark). After incubation, the cell suspensions were centrifuged, and the culture supernatant was stored at $-40^{\circ} \mathrm{C}$ until assayed for TNF.

\section{ASSAY OF TNF}

A modification of the cytotoxicity assay of Ruff and Gifford $^{11}$ was used to assay TNF activity. Briefly, mouse L-929 fibroblast cells, which are particularly sensitive to the cytotoxic activity of TNF, were plated in 96 well microtitre plates at a concentration of $3 \times 10^{4}$ cells $/ 0.1 \mathrm{ml} R P M I$ and incubated overnight at $37^{\circ} \mathrm{C}$. The next day, serial dilutions of the test supernatant were added to the incubated cells in the presence of $1.0 \mu \mathrm{g} / \mathrm{ml}$ of actinomycin D (Sigma Chemical Co, St. Louis, MO). The plates were incubated for 18 hours at $37^{\circ} \mathrm{C}$ in an atmosphere of $5 \% \quad \mathrm{CO}_{2}$ and then washed with saline. Cells were stained for 10 minutes with $0.2 \%$ crystal violet in a $20 \%$ methanol solution. The absorbance of each well at $590 \mathrm{~nm}$ was determined with an automatic microplate reader. One unit of TNF activity was defined as the amount required to lyse $50 \%$ of the L-929 target cells.

\section{STATISTICAL ANALYSIS}

Data on TNF obtained in the present study were assumed to be normally distributed. Values are expressed as the mean (SEM). The difference between means was evaluated with a $t$ test for independent groups.

\section{Results}

SCANNING ELECTRON MICROSCOPY OF MINERAL FIBRES

Scanning electron microscopy revealed that the ceramic fibres had an almost smooth surface and were straight and columnar. The chrysotile asbestos fibres had a rough surface, were curved, curly, or even coiled three dimensionally and were split longitudinally (fig 2).

\section{BRONCHOALVEOLAR LAVAGE}

The viability of cells recovered by bronchoalveolar lavage invariably exceeded $95 \%$ in both groups. A significantly greater number of total cells were recovered from rats exposed to smoke compared with unexposed rats. There were no significant differences in differential cell counts for the two groups. Alveolar macrophages accounted for $>97 \%$ of the cells in both groups (fig 3).

\section{PRODUCTION OF TNF BY ALVEOLAR MACROPHAGES} When alveolar macrophages were not stimulated by mineral fibres, the production of TNF in unexposed rats and rats exposed to smoke was essentially the same. Stimulation of alveolar macrophages with chrysotile significantly increased production of TNF and this was greater in smoke exposed than in unexposed rats (fig 4). When alveolar macrophages were stimulated by ceramic fibres, the difference was not significant.

Chrysotile produced concentration dependent increases in TNF production (fig 5). When alveolar macrophages were stimulated by 50 or $100 \mu \mathrm{g} / \mathrm{ml}$, TNF production in the rats exposed to smoke was significantly greater than in the unexposed rats.

Production of TNF in the rats exposed to smoke exceeded than in unexposed rats with all concentrations of ceramic fibres, but differences between the groups were not statistically significant (fig 6). 

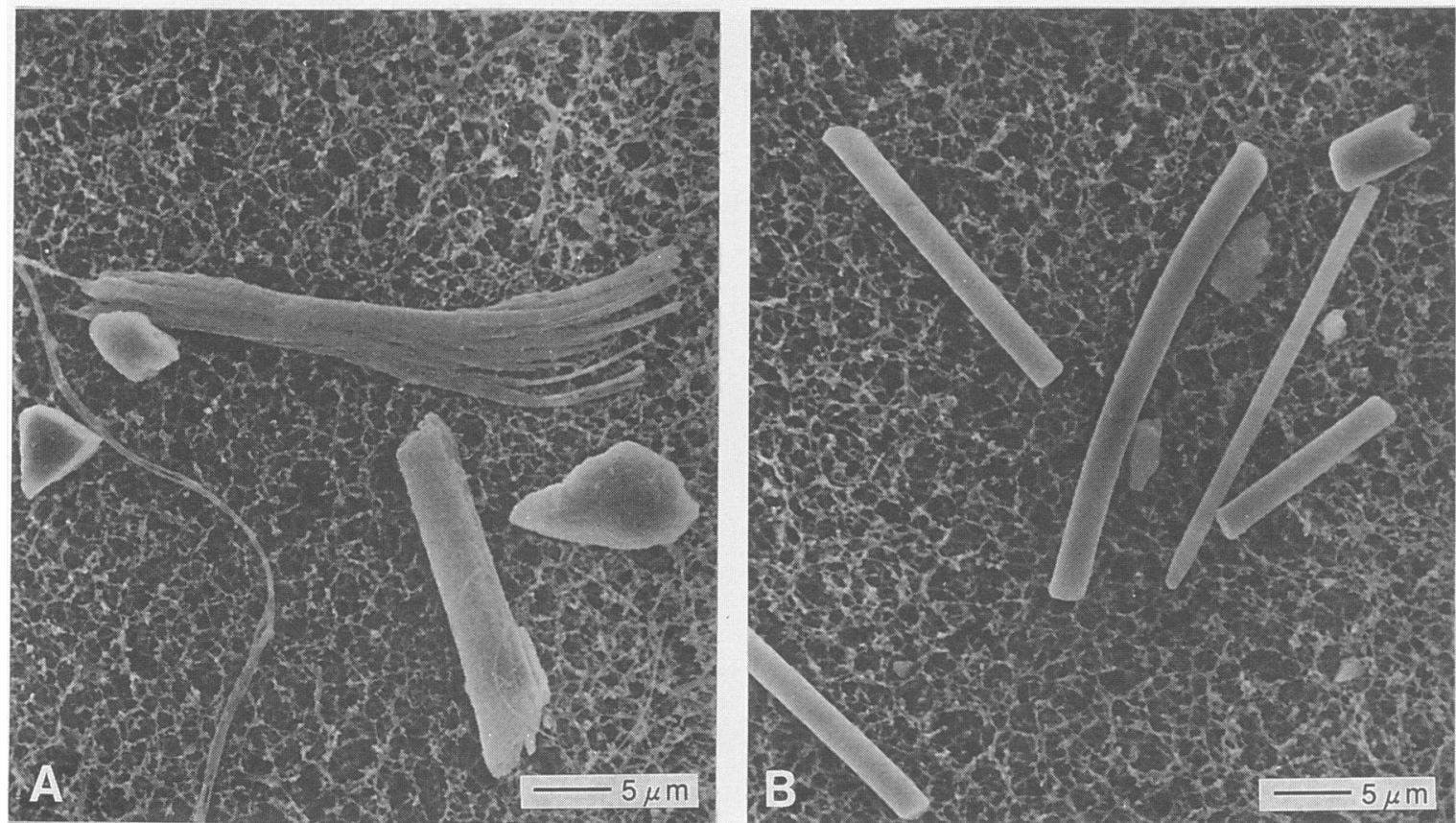

Figure 2 Scanning electron micrographs of mineral fibres: $(A)$ chrysotile, $(B)$ ceramic fibre (magnification $\times 4000$ ).

\section{Discussion}

Mcfadden et $a l^{12}$ have reported that the combined

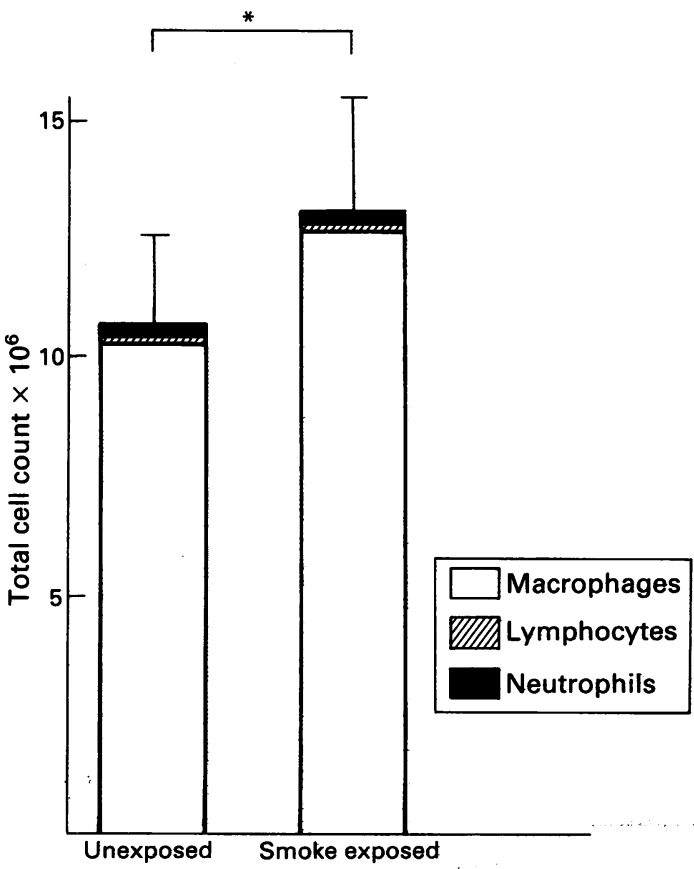

Fig 3 Total cell count and differential cell counts in bronchoalveolar lavage fluid from smoke exposed and unexposed groups. Values are mean (SEM). ${ }^{*} p<0.01$. effect of cigarette smoke and mineral fibres largely depends on disturbances in clearance of asbestos related to the effects of cigarette smoke. The study showed that in guinea pigs exposed to cigarette

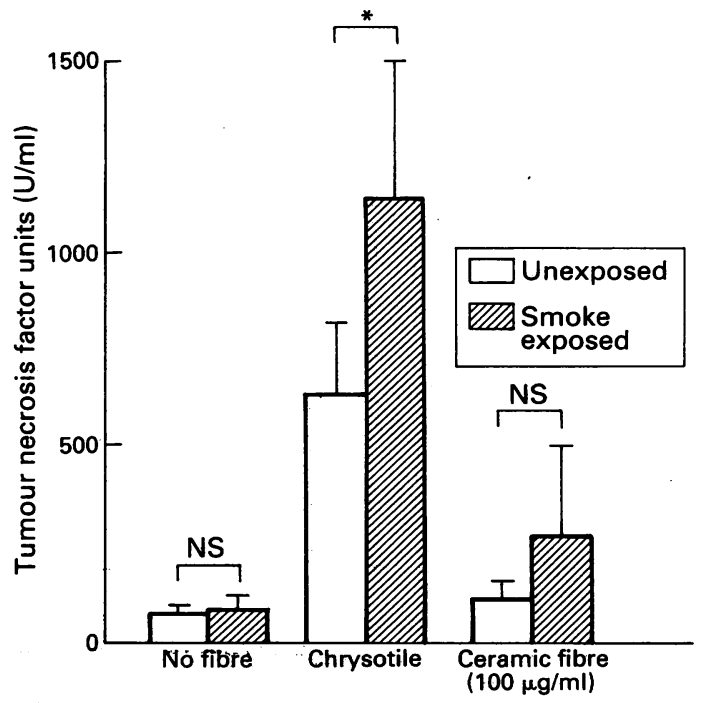

Fig 4 The effects of mineral fibres and cigarette smoke on TNF production by alveolar macrophages Values are mean (SEM). ${ }^{*} p<0.05$. 


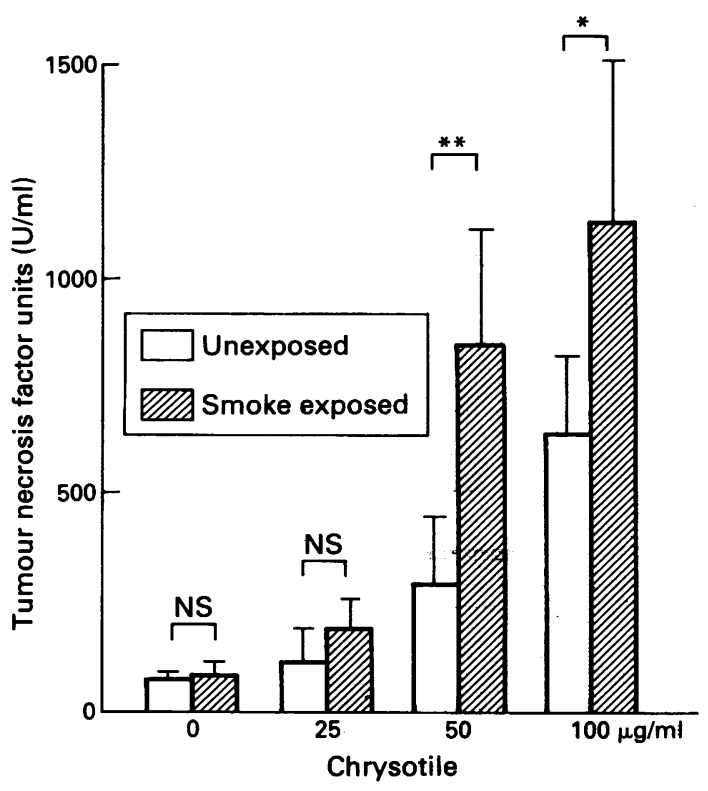

Fig 5 Concentration dependent stimulation of TNF production by chrysotile. Values are mean (SEM). ${ }^{*} p<0.05$; $\star_{p}<0.01$.

smoke after instillation of asbestos, the clearance of asbestos fibres from the lung was impaired. This finding suggests that smoking increases the risk of pulmonary asbestosis because it interferes with the clearance of asbestos fibres and therefore increases the effective fibre dose retained in the lungs.

Whereas some workers exposed to low amounts of asbestos develop the disorder, not all workers exposed to high amounts of asbestos are affected by asbestosis. Extrinsic factors, such as the retention of fibres in the lung, do not seem to explain the interaction between smoke and asbestos. Therefore, intrinsic factors including the host defence system, are believed to be responsible for differences in susceptibility.

Alveolar macrophages provide the principal defence against inhaled particulate materials in the lungs and play a primary part in mediating the inflammatory response. ${ }^{6}$ There is support for the view that asbestosis is the result of cellular injury associated with the release of enzymes from dead alveolar macrophages. $3-5$

Research on cytoactivation in the lung has suggested that homeostasis in the lung ${ }^{6}$ is controlled by a network of cell interactions and that alveolar macrophages play a key part in this homeostasis through signalling. Alveolar macrophages present antigen and send signals to other cells, leading to the production of activating factors, cell proliferation, and differentiation. An imbalance in signalling cells could lead to fibrosis. Interleukin-1 and TNF ${ }^{6}$

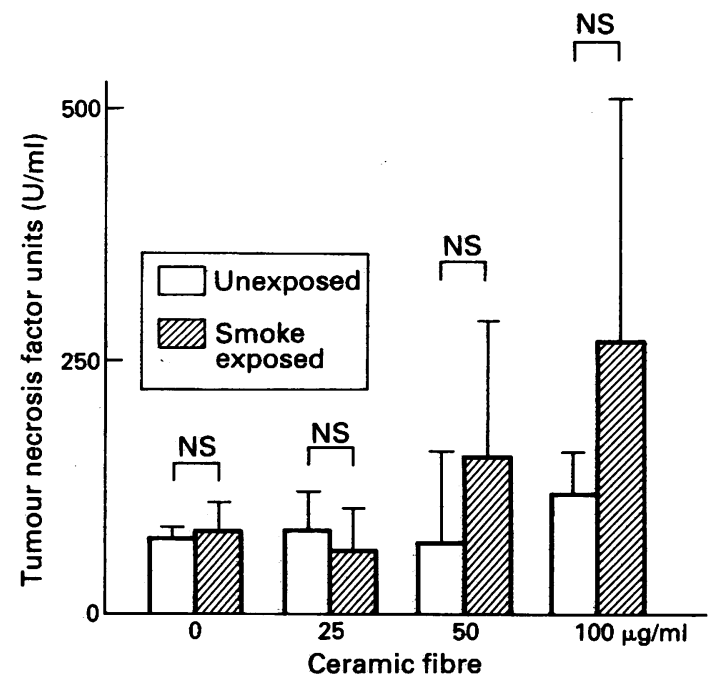

Fig 6 Concentration dependent stimulation of TNF production by ceramic fibres. Values are mean (SEM).

concentration are among the best indicators of cytoactivation in fibrotic processes. Because TNF has cytoregulatory effects, including the control of cell proliferation, it affects and attracts neutrophils, ${ }^{7}$ which injure lung tissue by producing superoxides and protease, and promoting fibroblasts.

Alveolar macrophages from an animal model of asbestosis produced significantly greater amounts of TNF than alveolar macrophages from controls, suggesting that TNF is involved in the fibrotic process. ${ }^{13}$ Dubois et al ${ }^{14}$ showed that asbestos induced production of TNF by alveolar macrophages in vitro. Our findings, showing that both chrysotile and ceramic fibres stimulated TNF production by alveolar macrophages, are consistent with the results of other studies.

Results of studies investigating the stimulation of production of interleukin-1 by cigarette smoke are conflicting. Smoking has been found to both induce ${ }^{15}$ and reduce interleukin-1 production. ${ }^{16} \mathrm{We}$ found that cigarette smoke alone did not stimulate production of TNF. When alveolar macrophages exposed to smoke were incubated with mineral fibres, however, the effects of the cigarette smoke enhanced the fibre-stimulated production of TNF. Both the ceramic and the chrysotile fibres tended to increase TNF production by alveolar macrophages in the smoke exposed and unexposed rats. Jackson et $\mathrm{al}^{17}$ reported that cigarette smoke and asbestos increased DNA damage synergistically and suggested that this synergism may involve $\cdot \mathrm{OH}$ production. Our results confirm these findings because TNF promotes superoxide production. ${ }^{6}$

It is not clear why cigarette smoke enhances the production of TNF in the presence of mineral 
fibres. Cigarette smoke has been found to affect alveolar macrophages by causing morphological changes, ${ }^{18}$ release of lactate dehydrogenase, and lysosomal enzymes, ${ }^{19}$ and the production of superoxides. ${ }^{20}$ Therefore, cigarette smoke causes activation of alveolar macrophages setting the stage for fibre-stimulated TNF production. Thus cigarette smoke may have a priming effect on mineral fibres. We found increased numbers of alveolar macrophages in association with exposure to cigarette smoke, suggesting that smoke activates the functions of alveolar macrophages. Studies in humans ${ }^{21}$ showed a significant increase in total cell count in bronchoalveolar lavage fluid from cigarette smokers and Matulionis ${ }^{22}$ reported that the inhalation of tobacco smoke by rats elicited a specific pulmonary recruitment of alveolar macrophages that had recently synthesised DNA.

Production of TNF differed significantly between treatments with chrysotile and ceramic fibres. Chrysotile stimulated greater TNF production by alveolar macrophages in both the group exposed to smoke and the unexposed group compared with ceramic fibres. This finding could be related to differences in the physical and chemical properties of the mineral fibres. Chrysotile possesses strong cytotoxic properties that are related to its surface charge, magnesium content, ${ }^{23}$ and crystalline silica content. ${ }^{24}$ On the other hand ceramic fibres, which have an amorphous structure, have few cytotoxic factors. Furthermore, scanning electron microscopy revealed surface differences between the chrysotile and ceramic fibres. Chrysotile fibres have a rough surface and tend to split longitudinally, whereas ceramic fibres have a smooth surface and a columnar shape. Chrysotile's surface properties may lead to a greater stimulation of alveolar macrophages because the fibres are able to make contact with the cell surface or the cytoplasm.

Our results showed that cigarette smoke and mineral fibres had a synergistic effect on the production of TNF by alveolar macrophages, supporting the epidemiological evidence that an interaction between smoking and exposure to asbestos affects the incidence of lung fibrosis.

Request for reprints to: Yasuo Morimoto, $\mathrm{MD}$, Division of Respiratory Disease, University of Occupational and Environmental Health, 1-1, Iseigaoka, Yahatanishiku, Kitakyushu 807, Japan.
1 Hammond EC, Selikoff IJ, Seidman H. Asbestos exposure, cigarette smoking and death rates. Ann NY Acad Sci 1979;330:473-90.

2 Weiss W. Cigarette smoke, asbestos, and small irregular opacities. Am Rev Respir Dis 1984;130:293-301.

3 Brody AR. Production of cytokines by particle-exposed lung macrophages. Cellular and molecular aspects of fiber carcinogenesis. Cold Spring Harbor: Cold Spring Harbor Laboratory Press, 1991: 83-102.

4 Davies $R$. The effect of mineral fibres on macrophages. In: Wagner JC, ed. Biological effects of mineral fibres. Lyons: International Agency for Research on Cancer 1980;1: 419-25. (IARC sci publ No 30).

5 Davies P, Allison AC, Ackerman J, Butterfield A, Williams S. Asbestos induces selective release of lysosomal enzymes from mononuclear phagocytes. Nature 1974;251:423-5.

6 Sibille Y, Reynolds HY. Macrophages and polymorphonuclear neutrophils in lung defense and injury. Am Rev Respir Dis 1990;141:471-501.

7 Kelley J. Cytokines of the lung. Am Rev Respir Dis 1990; 141:765-88.

8 World Health Organisation. Man-made mineral fibres. Environmental health criteria 77. Geneva: 1988: 11-32. (UNEP, ILO, and WHO publication.)

9 Morgan A, Black A, Evans N, Holmes A, Pritchard JN. Deposition of sized glass fibres in the respiratory tract of the rat. Ann Occup Hyg 1980;23:353-66.

10 Tanaka I, Ishimatsu S, Higashi T, Katoh T, Akiyama T. A passive tobacco smoke exposure system for laboratory animals. Foumal of University of Environmental Health 1990; 12:37-42.

11 Ruff MR, Gifford GE. Tumour necrosis factor. In: Pick E, ed. Lymphokine reports. London: Academic Press, 1981;2: 235-72.

12 Mcfadden D, Wright JL, Wiggs B, Churg A. Smoking inhibits asbestos clearance. Am Rev Respir Dis 1986;133:372-4.

13 Bissonnette E, Rola-Pleszczynski M. Pulmonary inflammation and fibrosis in a murine model of asbestosis and silicosis. Inflammation 1989;13:329-39.

14 Dubois CM, Bissonnette E, Rola-Pleszczynski M. Asbestos fibers and silica particles stimulate rat alveolar macrophages to release tumor necrosis factor. Am Rev Respir Dis 1989;139:1257-64.

15 Nagai S, Takeuchi $M$, Watanabe $K$, Aung $H$, Izumi $T$. Smoking and interleukin-1 activity released from human alveolar macrophages in healthy subjects. Chest 1988;94: 694-700.

16 Brown GP, Iwamoto GK, Monick MM, Hunninghake GW. Cigarette smoking decreases interleukin 1 release by human alveolar macrophages. Am f Physiol 1989;256:260-4.

17 Jackson JH, Schraufstatter IU, Hyslop PA, Vosbeck K, Sauerheber R, Weitzman SA, Cochrane CG. Role of oxidants in DNA damage. $\mathcal{F}$ Clin Invest 1987;80:1090-5.

18 Ando $M$, Sugimoto $M$, Nishi $R$, Suga $M$, Horio $S$, Kohrogi $H$, Shimazu K, Araki S. Surface morphology and function of human pulmonary alveolar macrophages from smokers and non-smokers. Thorax 1984;39:850-6.

19 Baughman RP, Corser BC, Strohofer S, Hendricks D. Spontaneous hydrogen peroxide release from alveolar macrophages of some cigarette smokers. $f \mathrm{Lab}$ Clin Med 1986;107:233-7.

20 Davis WB, Pacht ER, Spatafora M, Martin WJ. Enhanced cytotoxic potential of alveolar macrophages from cigarette smokers. f Lab Clin Med 1988;111:293-8.

21 Plowman PN. The pulmonary macrophage population of human smokers. Ann occup Hyg 1982;25:393-405.

22 Matulionis DH. Reaction of macrophages to cigarette smoke. 1. Recruitment of pulmonary macrophages. Arch Environ Health 1979;34:293-7.

23 Morgan A, Davies P, Wagner JC, Berry G, Holmes A. The biological effects of magnesium-leached chrysotile asbestos. Br F Exp Path 1977;58:465-73.

24 Bye E, Davies R, Griffiths DM, Gylseth B, Moncrieff CB. In vitro cytotoxicity and quantitative silica analysis of diatomaceous earth products. Br $\mathcal{F}$ Ind Med 1984;41:228-34.

Accepted 30 November 1992 